\title{
Schedule Risks Due to Delays in Advanced Technology Development
}

\author{
John D. Reeves, Jr. ${ }^{1}$ and Kamal A. Kayat ${ }^{2}$ \\ NASA Langley Research Center, Hampton, VA, 23681 \\ and \\ Evan $\operatorname{Lim}^{3}$ \\ Science Applications International Corporation, Sunnyvale, CA, 94087
}

\begin{abstract}
This paper discusses a methodology and modeling capability that probabilistically evaluates the likelihood and impacts of delays in advanced technology development prior to the start of design, development, test, and evaluation (DDT\&E) of complex space systems. The challenges of understanding and modeling advanced technology development considerations are first outlined, followed by a discussion of the problem in the context of lunar surface architecture analysis. The current and planned methodologies to address the problem are then presented along with sample analyses and results. The methodology discussed herein provides decision-makers a thorough understanding of the schedule impacts resulting from the inclusion of various enabling advanced technology assumptions within system design.
\end{abstract}

\section{Nomenclature}

$A_{n} \quad=$ Advanced technology development project

$A T D P=$ Advanced Technology Development Project

$b_{n} \quad=$ Initial TRL for ATDP A $_{\mathrm{n}}$

$C D F=$ Cumulative Distribution Function

$d_{n} \quad=$ Start date for ATDP n $_{\mathrm{n}}$

$D D T \& E=$ Design, Development, Test, and Evaluation

$D T=$ Delay time in DDT\&E start due to delayed technology development efforts

$E_{n} \quad=$ Project/Architecture Element

$E S A S=$ Exploration Systems Architecture Study

IOC $=$ Initial Operating Capability

$P D F \quad=$ Probability Density Function

$T \quad=$ Time

TTPM = Technology Technical Performance Metric

$T R L=$ Technology Readiness Level

WBS = Work Breakdown Structure

\section{Introduction}

$\mathrm{T}$ hroughout historical design and development of complex systems, unforeseen delays have frequently occurred due to engineering challenges, funding shortfalls, and inherent design optimism that have led to severe impacts on projected development schedules and costs. This behavior is damaging to all development investments but is particularly threatening to the development of multi-system architectures or infrastructures. Schedule relationships

${ }^{1}$ Aerospace Engineer, Vehicle Analysis Branch, Systems Analysis and Concepts Directorate, NASA Langley Research Center, AIAA Member.

${ }^{2}$ Langley Aerospace Scholar, Space Missions Analysis Branch, Systems Analysis and Concepts Directorate, NASA Langley Research Center, AIAA Member.

${ }^{3}$ Consultant. 
are pervasive when various systems within such architectures are dependent on each other for either inclusion (i.e., subsystem within larger system) or for production requirements (i.e., concurrent production plans). Schedule delays within one system of a multi-system architecture will at best cause holding delays to other related systems, while at worst could lead to reduced and inadequate funding for other systems due to reallocation of resources to mitigate the cause of the original delay. In addition to delays inherent with traditional system development, pre-requisite development of advanced technologies is severely prone to experiencing delays due to additional work aimed at squeezing every bit of promised benefits from such investment, which often is crucial for the system's overall feasibility. By their very nature, advanced technologies carry a large amount of uncertainty associated with their benefits (e.g., performance improvements) as well as their costs and schedules. Historical examples have often demonstrated that entire development projects can be delayed while issues are worked out with assumed technology development paths.

\section{Technology Development Challenges}

\section{A. Advanced Technology Development Considerations within Design}

The inclusion of advanced technologies within complex system design presents design engineers with numerous challenges due to the uncertain nature of how such technologies will impact their systems. Not only do the positive impacts have to be predicted (in the form of improved performance characteristics, lessened maintainability demands, etc.), but the associated development cost and development risk have to be appropriately considered. It is easy to focus on the benefits since doing so typically expands the design space and in many cases actually enables design feasibility. However the benefits in many cases can quickly be eroded by increased costs, schedule, and associated uncertainties, requiring careful cost/benefit analyses. In addition, the benefits and penalties associated with advanced technologies are very often highly interrelated. When a technologist advertises the benefits of a particular advanced technology, an assumption is made that such return on the investment (the further development of said technology being the investment) is based on some certain threshold of funding. If such a development program is funded at a lesser rate or schedule, the claimed benefits of inclusion can fall critically short. This, in addition to the inherent nature of technology benefits to fall short due to elusive technological breakthroughs, spurious starting assumptions, and other considerations, fosters a scenario where costs can far exceed promised benefits.

This is not to say that the inclusion of advanced technologies within complex system design is to be avoided. In fact the exact opposite is often warranted for it allows genuine progress to be made within scientific and engineering communities and enables systems to achieve increasingly demanding performance levels. Systems with razor thin mass margins such as space transportation and lunar surface systems almost always require advanced technology fruition to enable feasibility. Design decisions made early during the design process tend to drive overall system behavior, so systems engineering is not complete without appropriate focus on technology development. Since technology development is such a prominent life cycle consideration in its own right, it can be considered a separate discipline from traditional systems engineering. "Technology Engineering" is the subject of both a significant amount of academic research and dedicated development programs (dedicated in the sense that they are funded and tracked separately from the system(s) that they will ultimately be incorporated in). ${ }^{1}$ There is also a wide range of consideration given to how to "select" which technologies will be incorporated into a system's development; thus there is a myriad of published technology assessment and prioritization techniques. ${ }^{2-7}$

The assessment of advanced technology inclusion has been discussed from numerous perspectives, but Stanley and Wilhite lay out a technology engineering framework that accurately portrays the various phases of identifying and including space transportation technologies within the larger realm of systems engineering: ${ }^{1}$

1. Technology Requirements Development and Analysis

2. Technology Prioritization and Initial Selection

3. Technology Program Planning

4. Technology Program Monitoring and Management

5. Technology Integration and Insertion

"Technology Requirements Development and Analysis" deals with the identification of system requirements gaps in combination with potential technology development solutions that could mitigate such gaps. Once the gaps have been identified and a pool of potential technology solutions has been identified, the "Technology Prioritization and Initial Selection" phase contains the actual prioritization and screening of candidates leading to a technology investment portfolio. The "Technology Program Planning" and "Technology Program Monitoring and 
Management" phases capture the programmatic considerations of laying out and monitoring appropriate roadmaps and milestones associated with the aforementioned portfolio. The final "Technology Integration and Insertion" phase pertains to the final verification that the selected technology development paths have matured to the appropriate level and will provide promised benefits while maintaining planned costs, and that they are ready for inclusion within larger system DDT\&E.

Throughout all five phases a common theme exists in that all technology candidates have to be measured using quantifiable impact characterizations that allow comparison to target system requirements. Stanley refers to the use of Technology Technical Performance Measures (TTPMs) that represent a "subsystem- or component-level parameter that is readily measurable during the implementation of a given technology project by a knowledgeable technologist", while other research uses other names such as "k-factors" to represent the same concept. ${ }^{3,4}$ These impact characterizations quantitatively relate how a given technology will impact a particular system in terms of performance, reliability, maintainability, development cost, operational costs, and so forth. They also allow engineers to understand the trade-offs associated with the inclusion of such technology, thus enabling the prioritization process. Since so much uncertainty surrounds the fruition of advanced technologies, all such impact characterizations should take the form of distributions as opposed to point prediction estimates. In addition to the impacts to a larger system, each technology development candidate carries additional characteristics that are highly related to, but somewhat independent of, the system impacts. These characteristics are related more to a development program itself required to mature said technology to the point where it can be incorporated within a larger system. These characteristics include, but are not limited to, the current maturity level of the technology, the cost and schedule required to mature it to the point where it can be used, and so forth. This latter set of characteristics, pertaining to the development effort itself, is of interest in understanding the potential schedule impacts such development efforts could have on full DDT\&E schedules for complex systems.

\section{B. Relationship Between Technology Development and Traditional System Development}

To understand how various advanced technologies could potentially influence a system's development, a characterization of the current maturity level of each technology is used. The Technology Readiness Level (TRL) ${ }^{8}$ provides standardized insight into the maturity level and is commonly used throughout the aerospace community. Mathias et al. propose an alternative scale that is more consistent with how historical technology development data can be collected; i.e., is more in-line with development program milestones. ${ }^{9}$ The two scales are similar in nature and can be seen in Fig. 1.

\begin{tabular}{|c|l|}
\hline Level & $\begin{array}{l}\text { Definition of Technology Readiness Bins } \\
\text { (Mathias, Goodsell, Go) }\end{array}$ \\
\hline 6 & Operation Production \\
\hline 5 & System Qualification / Flight Test \\
\hline 4 & Subsystem Qualification / System Testing \\
\hline 3 & Technology Demonstration \\
\hline 2 & Technology Development \\
\hline 1 & Basic Research \\
\hline
\end{tabular}

\begin{tabular}{|c|c|}
\hline Level & Definition of Technology Readiness Level (Mankins) \\
\hline 9 & $\begin{array}{l}\text { Actual system "flight proven" through successful mission } \\
\text { operations }\end{array}$ \\
\hline 8 & $\begin{array}{l}\text { Actual system completed and "flight qualified" through test and } \\
\text { demonstration (ground or space) }\end{array}$ \\
\hline 7 & System prototype demonstration in a space environment \\
\hline 6 & $\begin{array}{l}\text { System/subsystem model or prototype demonstration in a relevant } \\
\text { environment (ground or space) }\end{array}$ \\
\hline 5 & Component and/or breadboard validation in relevant environment \\
\hline 4 & Component and/or breadboard validation in laboratory environmen \\
\hline 3 & $\begin{array}{l}\text { Analytical and experimental critical function and/or characteristic } \\
\text { proof-of-concept }\end{array}$ \\
\hline 2 & Technology concept and/or application formulated \\
\hline 1 & Basic principles observed and reported \\
\hline
\end{tabular}
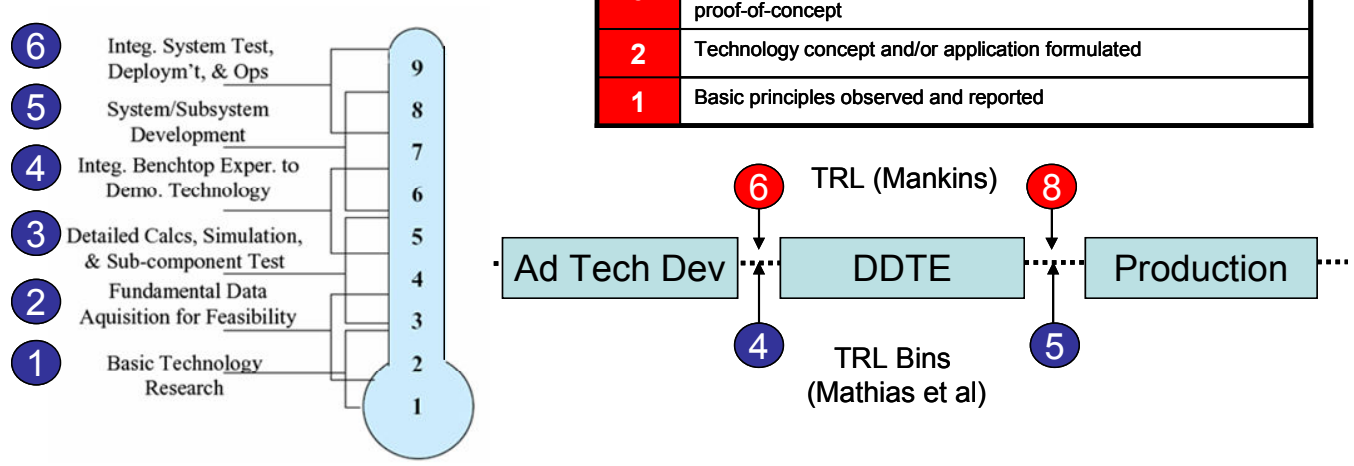

Figure 1. Translation Between TRL and TR Bins. 
Both the traditional TRL scale and the TR Bin scale capture the full life cycle of a technology's development through actual production and operation of the system or vehicle that it ultimately supports. However, full vehicle DDT\&E generally assumes that all advanced technologies are at a TRL level of at least 6 (i.e., system/subsystem model or prototype has been demonstrated in a relevant environment) so the upper portion of the traditional TRL scale (TRLs 7-9) can be assumed to be contained within the vehicle's DDT\&E effort. This can also be seen in the bottom right portion of Fig.1. where the red TRL 6 and TRL 8 identifiers identify how they relate to vehicle DDT\&E. The TR Bin identifiers are also included so it can be deduced that a TRL value of 6 equates to a TR Bin value of 4 , and that both indicate how mature a technology should be in order to be included in vehicle DDT\&E. Likewise, TRL 8 equates to TR Bin 5, and indicates the assumed maturation of such technology once the vehicle is fully developed and ready for production. It is crucial to understand these relationships when attempting to forecast expected behavior of technology development programs and their relationship to vehicle DDT\&E efforts.

\section{Using Historical Data to Forecast Future Behavior}

Since uncertainty is pervasive throughout all advanced technology considerations, appropriate modeling requires distributions around virtually every assumption. The quantification of actual benefits and costs associated with inclusion of technologies within a complex system or vehicle requires stochastic analysis in addition to the understanding of how each technology will impact the system from a technical perspective. A technical understanding of the system and how it is impacted by technology inclusion is typically based on traditional systems engineering disciplines. However, the characteristics associated with the technology development efforts themselves, such as the cost and schedule to mature a technology to TRL $=6 / T R$ Bin $=4$, cannot be solely based on a technical understanding of the system or technology. Each historical example "represents a 'real' scenario that included the effects of real budgets, political environments, and technical difficulties". ${ }^{9}$ By relating a future advanced technology candidate to similar past efforts, an understanding of expected behavior can be deduced. The additional challenge therein exists in that it is extremely difficult to collect historical data in such a way to completely understand what drove each example in terms of cost and schedule. Several historical data considerations can be seen in Table 1.

Table 1. Considerations in Understanding Historical Technology Development Examples.

\begin{tabular}{cl}
\hline Historical Data Consideration & \multicolumn{1}{c}{ Description } \\
\hline Adequacy of Funding & Was the technology development funded at an optimal level? \\
\hline Push vs. Pull & Was it developed as a need or for its own benefit? \\
\hline Enabling vs. Enhancing & $\begin{array}{l}\text { Did it enable an actual system's feasibility, or did it just } \\
\text { enhance some technical attribute? }\end{array}$ \\
\hline
\end{tabular}

The adequacy of funding is important for it provides insight into whether a technology development effort was funded at an optimal level versus either a crash-effort or a case where the effort was kept alive at some minimal level until additional money became available. Another consideration is whether a technology development effort was required by a particular vehicle being developed versus being developed in hopes of finding a future application. Finally, if a technology was included on a vehicle after maturing to the appropriate point, it should be noted whether or not it was an enabling technology for vehicle feasibility versus an enhancing technology included to boost some attribute, such as a performance metric that already met design requirements. These considerations are examples of issues that may have significantly driven past technology development behavior. Of course it is difficult to assess actual causality, but historical data collection should attempt to capture these and similar characterizations.

\section{Problem Context}

In January of 2004 the President of the United States announced a new space exploration vision for NASA to extend human presence across the solar system, starting with a human return to the Moon by the year 2020, in preparation for human exploration of Mars and other destinations. To implement this vision, the development of innovative technologies, knowledge, and infrastructures are needed both to explore and to support decisions about the destinations for human exploration.

The Constellation Systems Program was launched to implement the findings and recommendations assessed by the Exploration Systems Architecture Study (ESAS) team into a sustainable human space program. ${ }^{10}$ The success of the program is critically dependent on the successful development of various new technologies both originally envisioned during ESAS and later revised as requirements changed and designs matured. Success is also dependent on the successful development and integration of a multi-element architecture since the original exploration 
architecture consisted of a human-rated Crew Exploration Vehicle (CEV), a Lunar Surface Access Module (LSAM), a human-rated Crew Launch Vehicle (CLV), a Cargo Launch Vehicle (CaLV) which includes the Earth Departure Stage (EDS), Ground Systems, Missions Systems, and future destination surface systems such as habitats, power systems, rovers, science equipment, robotic systems, and resource utilization systems that enable the crewmembers to live, work and explore the surface of other worlds. Many of these elements have since become project offices within the Constellation Program, and have been given new nomenclatures (e.g., the Orion Crew Vehicle (CEV), Ares Launch Vehicles (CLV and CaLV), and the Altair Lunar Lander).

The multi-element aspect of the Constellation Architecture lends itself to numerous instances where a delay in one element's development could lead to significant delays in other elements. The upcoming Orion and Ares I combination is an example since a delay in either could potentially delay the Initial Operating Capability (IOC) date for the other. Another pervasive example of this interrelationship is within the lunar surface sub-architecture, which is part of the Constellation Program, but can be thought of as an architecture in its own right due to various systems that have to be both developed and delivered to the lunar surface in coordinated fashion. Of course all lunar systems are dependent on the development of the transportation system to deliver them in the first place, but assuming the transportation capability is available as planned, a large amount of consideration has to be given to how delays within certain lunar systems could impact others.

When planning a lunar architecture, decision makers have to balance an appropriate amount of advanced technology inclusion with potential inter-related delays that would be expected. A distribution of the time required to reach set milestones within system development projects is needed to account for schedule uncertainty associated with technology maturation. These distributions would provide insight into how the inclusion of various advanced technologies may impact planned costs and schedules. In addition to milestone distributions, supporting data could include statistical characteristics such as confidence intervals that indicate the credibility of an estimate, and sensitivity analysis results which could verify the stability of the assumptions.

To arrive at this level of understanding, one has to determine the driving factors by probabilistically combining the likelihood and impacts of delays in advanced technology development prior to the start of DDT\&E for various architecture elements. The intent would be to understand differences between planned and estimated initial operating dates of systems within an architecture. This could be accomplished by comparing historical examples of technology maturation efforts to identify key driving factors which can then be used to make predictions on how future technology development investments would pan out.

Both planned and historical technology data are required since the analysis would compare technology investments (or investment candidates) currently being planned versus how similar examples have behaved in the past. In the case of the NASA's Constellation lunar surface architecture, a list of identified technologies associated with the various architecture elements would be analyzed along with inter-relationships between the elements themselves and the technology investment paths. Within the planned list of technology investments, data can be assembled from several technology sectors, such as: propulsion, suit development, power generation, radiation shielding, cryogenic fuel storage, habitat development, and surface mobility. However, most new technologies cannot be directly matched to any past projects. Hence, surrogate past technology development projects could be used within the analysis as indicators of how the current efforts may behave. For example, consider the construction of a lunar habitat. Thus far, there has never been a permanent habitable structure assembled on the moon. On the other hand, several extreme environment research habitats exist on earth, such as arctic and undersea habitats that are currently being occupied and used by scientists, researchers, and explorers. The technologies utilized and the lessons learned from technology inclusion within these systems could be applied to the development of a lunar habitat.

The success of the space exploration program is dependent on managing the development of new technologies and accounting for the uncertainty inherent within the process. Historical design and development of complex systems prove that there is no assurance that by just identifying and funding a technology, it will progress on time to have the necessary performance capabilities and stay within the allocated budget. The following discussion lays out an emerging capability to leverage historical technology development efforts to understand future investments.

\section{Methodology}

The basic methodology for quantitatively estimating the schedule risk of a project element as a function of TRLs was described by Mathias et al. ${ }^{9}$ The current study extends that approach to model large projects encompassing multiple elements where each element may require a number of pre-requisite Advanced Technology Development Projects (ATDPs). The five calculation steps of this analysis are: 
1. Create a project level work breakdown structure (WBS) with its constituent elements (e.g.,, Unpressurized Rover)

2. Identify the pre-requisite ATDPs for each element in the WBS

3. Quantify the following characteristics of each ATDP:

a. Planned start date of the ATDP

b. TRL level at the start date of the ATDP

c. Time needed to mature from one TRL level to another

4. For each element, estimate the date when all of its required ATDPs reach the point where they are ready to begin DDT\&E. On the Mankins TRL scale, this corresponds to TRL $=6$ which is defined as "System/subsystem model or prototype demonstration in a relevant environment (ground or space)". If this date is later than the date originally planned, the difference between the planned and actual dates is the schedule slip for that element.

5. Assess the delays associated with the individual elements to estimate the delay of the overall project

The first step is to assemble a WBS of the overall project. The highest level of the WBS typically corresponds to the major elements or functional requirements of the project. The WBS may be identical or similar to the WBS used by project management and/or cost analysts.

After the WBS is defined, the pre-requisite ATDPs for each element are identified and characterized with the assumption that each identified ATDP will achieve a TRL of 6 by the time the element's DDT\&E begins. The list of ATDPs may be compiled using input from project engineering and staff familiar with the ATDPs, or could be the result of a technology prioritization process as mentioned in Section II of this paper. Some ATDPs may be prerequisites to more than one project element. This step may identify gaps in technology where additional ATDPs should be initiated.

The third step is to characterize each ATDP with three pieces of information:

1. Planned start date of the ATDP

2. TRL of the ATDP on its start date

3. Time needed for the ATDP to mature from its initial TRL $(=j)$ to its required TRL $(=6)$. The time may be estimated by summing the times needed to transition from one TRL to the next, or

$$
T(j \rightarrow 6)=T(j \rightarrow j+1)+\ldots+T(5 \rightarrow 6)
$$

When an element requires one or more ATDPs, the start date of DDT\&E for that element is equal to the latest (maximum) date that any individual ATDP achieves the desired TRL $=6$. If the element consists of $n$ ATDPs, the time to reach $\mathrm{TRL}=6$ is given by

$$
T(6, \text { Element })=\max \left(T\left(6, A T D P_{1}\right), T\left(6, A T D P_{2}\right), \ldots, T\left(6, A T D P_{n}\right)\right)
$$

Figure 2 uses two elements named $\mathrm{E}_{1}$ and $\mathrm{E}_{2}$ to illustrate steps 1, 2 and 3. Element $\mathrm{E}_{1}$ requires three ATDPs, named $A_{1}, A_{2}$ and $A_{3}$. $E_{2}$ only requires $A_{3}$ which was also required by $E_{1}$. The TRL values of the ATDPs are shown in the circles on the timelines for the ATDPs. $E_{1}$ starts its DDT\&E when $A_{2}$ reaches TRL $=6$ because $A_{2}$ is the ATDP that finishes last. Similarly, $\mathrm{E}_{2}$ starts its DDT\&E when $\mathrm{A}_{3}$ reaches $\mathrm{TRL}=6$. 


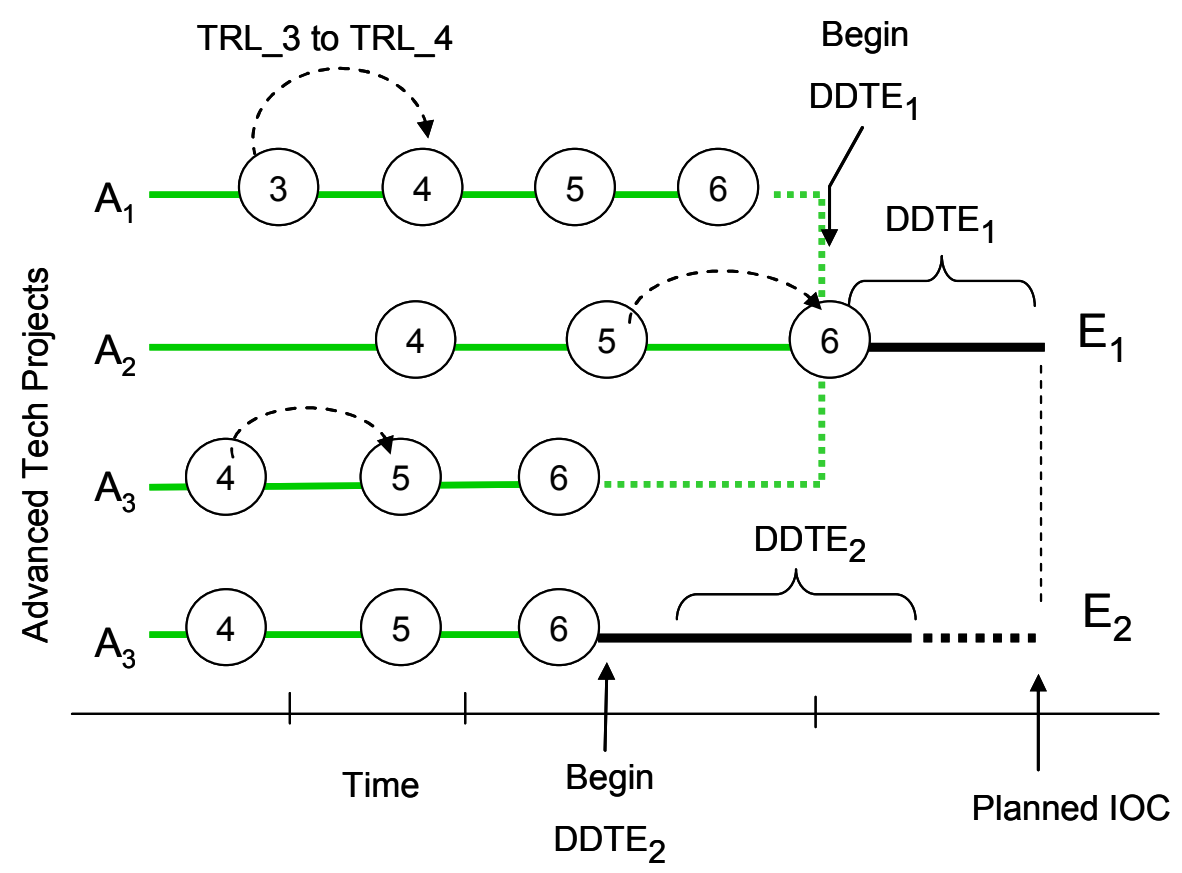

Figure 2. Timeline of WBS Elements and Pre-requisite ATDPs.

Since ATDPs are generally first of a kind engineering designs, historical data on development times of identical items obviously do not exist. The best sources of information are historical data from analogous projects or subjective judgments by subject matter experts. Data on analogous projects may be pulled from diverse sources such as official project documentation, scientific journals, newspaper items, and magazine articles. These sources typically do not provide neatly defined TRL values at key milestones. Instead, they may be vague, inconsistent and subject to interpretation by the analysts. Even when there are a number of independent and consistent sources, gaps may still exist in the project chronology.

Once a set of data has been compiled for an advanced technology, regression analysis is used to reduce that data into a set of descriptive statistics such as the mean, variance, and percentiles of the time needed to transition from one TRL level to another.

The data required for steps 1, 2 and 3 may be organized as shown in Table 2, Table 3, and Table 4. Table 2 shows which ATDPs are assigned to each element as well as the initial TRL and start date of the ATDPs. Table 3 shows which historical data sets are used by each ATDP in calculating the time to reach TRL $=6$. Table 2 and Table 3 are linked through the ATDPs which are listed in the first column of each table. Table 4 represents the historical data. Each row is a historical data set and each cell is the time needed to jump from one TRL to another. The time may be a single value or a probability distribution of likely times.

Table 2. ATDP to Elements Matrix.

\begin{tabular}{|c|c|c|c|c|c|c|c|c|}
\hline \multirow{2}{*}{$\begin{array}{l}\text { Adv } \\
\text { Tech }\end{array}$} & \multirow{2}{*}{$\begin{array}{c}\text { Initial } \\
\text { TRL }\end{array}$} & \multirow{2}{*}{$\begin{array}{l}\text { Start } \\
\text { Date }\end{array}$} & \multicolumn{6}{|c|}{ Project Elements } \\
\hline & & & $\mathbf{E}_{1}$ & $\mathbf{E}_{2}$ & $\ldots$ & $\mathbf{E}_{\mathbf{n}}$ & $\ldots$ & $\mathbf{E}_{\mathrm{N}}$ \\
\hline $\mathrm{A}_{1}$ & $\mathrm{~b}_{1}$ & $\mathrm{~d}_{1}$ & $\mathrm{x}$ & & $\mathrm{x}$ & & & $\mathrm{x}$ \\
\hline $\mathrm{A}_{2}$ & $\mathrm{~b}_{2}$ & $\mathrm{~d}_{2}$ & $\mathrm{x}$ & $\mathrm{x}$ & & $\mathrm{x}$ & & \\
\hline$\ldots$ & & & & & & & $\mathrm{x}$ & \\
\hline $\mathrm{A}_{\mathrm{m}}$ & $\mathrm{b}_{\mathrm{m}}$ & $\mathrm{d}_{\mathrm{m}}$ & & & & & $\mathrm{x}$ & $\mathrm{x}$ \\
\hline$\ldots$ & & & $\mathrm{x}$ & & $\mathrm{x}$ & & & \\
\hline $\mathrm{A}_{\mathrm{M}}$ & $b_{M}$ & $d_{M}$ & & & & $\mathrm{x}$ & & \\
\hline
\end{tabular}


Table 3. ATDP to Historical Data Set Matrix.

\begin{tabular}{|c|c|c|c|c|c|c|c|c|}
\hline \multirow{2}{*}{$\begin{array}{c}\text { Adv } \\
\text { Tech } \\
\end{array}$} & \multicolumn{8}{|c|}{ Historical Data Sets } \\
\hline & $\mathbf{h}_{1}$ & $\mathbf{h}_{2}$ & $\ldots$ & $\ldots$ & $\ldots$ & $\ldots$ & $\ldots$ & $\mathbf{h}_{L}$ \\
\hline $\mathrm{A}_{1}$ & $\mathrm{x}$ & & & & & & & \\
\hline $\mathrm{A}_{2}$ & & & $\mathrm{x}$ & & & & & \\
\hline$\ldots$ & & & $\mathrm{x}$ & & & & & \\
\hline$A_{m}$ & & & & & $x$ & & & \\
\hline$\ldots$ & & & & & & & & \\
\hline$A_{M}$ & & & & & & & & $\mathrm{x}$ \\
\hline
\end{tabular}

Table 4. TRL Transition Times.

\begin{tabular}{|c|c|c|c|c|c|}
\hline \multirow[b]{2}{*}{$\begin{array}{c}\text { Data } \\
\text { Sets }\end{array}$} & \multicolumn{5}{|c|}{ Time to Transition from One TRL Level to the Next } \\
\hline & TRL (1 to 2) & .. & TRL (5 to 6) & . & TRL (8 to 9) \\
\hline $\mathrm{h}_{1}$ & $t_{t\left(h_{l}, l \rightarrow 2\right)}$ & & $t\left(h_{l}, 5 \rightarrow 6\right)$ & & $t_{t}\left(h_{l}, 8 \rightarrow 9\right)$ \\
\hline $\mathrm{h}_{2}$ & $t\left(h_{2}, 1 \rightarrow 2\right)$ & & $t\left(h_{2}, 5 \rightarrow 6\right)$ & & $t\left(h_{2}, 8 \rightarrow 9\right)$ \\
\hline$\frac{\ldots}{h_{L}}$ & $t\left(h_{L}, l \rightarrow 2\right)$ & & $t\left(h_{L}, 5 \rightarrow 6\right)$ & & $t\left(h_{L}, 8 \rightarrow 9\right)$ \\
\hline
\end{tabular}

In a deterministic analysis, the average time needed to reach $\mathrm{TRL}=6$ is estimated as the sum of the average times for each of the individual TRL transition steps. If the estimated date when the element reaches TRL $=6$ exceeds the originally planned date, the start of DDT\&E is delayed. The schedule slip is the difference between the estimated and originally planned dates, or

$$
\begin{array}{llll}
\text { Delay } & =0 & & \text { if } T(6, A T D P) \leq T(6, \text { planned }) \\
& =T(6, \text { estimated })-T(6, \text { planned }) & & \text { if } T(6, A T D P)>T(6, \text { planned })
\end{array}
$$

For probabilistic calculations, a numerical simulation such as Monte Carlo is normally required. In each trial of the simulation, the time it takes the ATDPs to reach TRL $=6$ is obtained by sampling the times needed to transition from one level to the next and summing the results. Probabilistic results are presented either as a probability distribution function (PDF) or cumulative distribution function (CDF).

In the simplest case of no time dependencies between the elements, the schedule slip of the overall project is determined by adding the delays and penalties of the various elements. For a probabilistic analysis, the new schedule is obtained by simulating a large number of scenarios using the probability distributions for the ATDP maturity times.

\section{Sample Analysis Results}

This section describes how the methodology outlined was used to analyze schedule risk in NASA's Constellation project. Past research by Mathias et al. ${ }^{9}$ and Forgie and Evans ${ }^{11}$ has included collection of historical data with regression analysis to organize it into various bins applicable to current Constellation needs. The data in this sample are notional and are not representative of the actual project values. The numerical algorithm, including random seed generation, was implemented in Microsoft Excel ${ }^{\circledR}$.

The sample analysis evaluates the schedule risk of the planned IOC date for the Constellation program's lunar architecture if pre-requisite ATDPs are delayed. To simplify this analysis, the following assumptions have been made:

- The time needed to transition from one TRL to another within a particular ATDP is normally distributed

- TRL transitions from DDT\&E to IOC are not modeled 
The WBS for this sample analysis contains the following notional surface system elements: Habitat, Pressurized Logistics Module, Unpressurized Rover, Pressurized Rover, and Power System.

The data used in this sample analysis are shown in Tables 5-7. Table 5 shows the five elements of the WBS along with the planned duration of the DDT\&E and planned IOC date. In this example, the elements assume a common IOC date of 2020 and a standard DDT\&E duration of 4 years. The planned DDT\&E start date of 2016 is obtained by subtracting the DDT\&E duration from the IOC date. All of the ATDPs associated with an element must reach $\mathrm{TRL}=6$ (or greater) before the planned DDT\&E start date.

Table 6 lists the ATDP elements and the WBS elements. ATDPs are linked to a WBS element by entering a nonzero value into the cell where the WBS element column and ATDP row intersect. For example, the pre-requisite ATDPs for the Habitat element are A1, A2, A3, A4 and A5. This table also shows the following information for each ATDP:

- $\quad$ historical data set which characterizes the time to mature from one level to another

- the TRL of the ATDP at the start of the ATDP

- the start for the ATDP

Table 7 is the database of notional historical transition times used in this analysis. This database uses the TR "bins" structure originally proposed by Mathias. There are 6 bins instead of 9 levels as in the Mankins formulation. The conversion between TR bins and TRLs was shown in Fig 3. Since most of the literature uses the 9 level TRL formulation, this model assumes that the initial technology readiness of an ATDP is also expressed on the 9-level scale. The conversion to the 6-bins is performed internally by the software and is completely transparent to the user. It can also be seen that the list of historical technologies in Table 7 is not referenced in its entirety in Table 6 . This demonstrates that the ATDP list only pulls historical comparisons that are germane, and that the entire set of historical data is not be needed.

Table 5 also shows the likelihoods that the elements have reached IOC as a function of time with delays attributed to the multiple advanced technology developments associated with each element. In the example, there is a $68 \%$ likelihood that the Habitat element achieves IOC by the end of 2020 as originally planned. The likelihood increases to $88 \%$ and $95 \%$ by 2021 and 2022 respectively. The pressurized logistics module has only a $38 \%$ likelihood of being at IOC by its originally planned date of 2020 . The likelihood rises gradually to $60 \%, 77 \%$ and $89 \%$ in 2021, 2022 and 2023, respectively. Note that likelihood for reaching IOC prior to the planned date is zero because the current model does not accelerate the DDT\&E start date if the pre-requisite ATDPs are completed earlier than planned.

Table 5. Example Results per Architecture Element (Notional).

\begin{tabular}{|c|c|c|c|c|c|c|c|c|c|c|c|c|}
\hline \multirow[b]{2}{*}{ Constellation Elements } & \multirow[b]{2}{*}{$\begin{array}{c}\text { DDT\&E } \\
\text { (yrs) }\end{array}$} & \multirow[b]{2}{*}{$\mathrm{IOC}$} & \multicolumn{10}{|c|}{ Likelihood of Reaching IOC (=completion of DDT\&E) } \\
\hline & & & 2018 & 2019 & 2020 & 2021 & 2022 & 2023 & 2024 & 2025 & 2026 & 2027 \\
\hline Habitat & 4.0 & 2020 & 0.00 & 0.00 & 0.68 & 0.88 & 0.95 & 0.98 & 0.99 & 1.00 & 1.00 & 1.00 \\
\hline Pressurized Logistics Module & 4.0 & 2020 & 0.00 & 0.00 & 0.38 & 0.60 & 0.77 & 0.89 & 0.95 & 0.98 & 0.99 & 1.00 \\
\hline Unpressurized Rover & 4.0 & 2020 & 0.00 & 0.00 & 0.52 & 0.69 & 0.82 & 0.90 & 0.95 & 0.98 & 0.99 & 1.00 \\
\hline Pressurized Rover & 4.0 & 2020 & 0.00 & 0.00 & 0.47 & 0.63 & 0.77 & 0.87 & 0.93 & 0.97 & 0.98 & 0.99 \\
\hline Power System & 4.0 & 2020 & 0.00 & 0.00 & 0.43 & 0.66 & 0.82 & 0.92 & 0.97 & 0.99 & 1.00 & 1.00 \\
\hline
\end{tabular}


Table 6. ATDP to Element Relationships (Notional).

\begin{tabular}{|c|c|c|c|c|c|c|c|}
\hline $\begin{array}{c}\text { Advanced } \\
\text { Tech Project }\end{array}$ & Category & $\begin{array}{c}\text { Data } \\
\text { Set }\end{array}$ & Yes & Yes & Yes & Yes & Yes \\
\hline A1 & Habitat & $\mathrm{H} 11$ & 1 & & & & \\
\hline A2 & Habitat & $\mathrm{H} 12$ & 1 & & & & \\
\hline A3 & Habitat & $\mathrm{H} 13$ & 1 & & & & \\
\hline A4 & Habitat & $\mathrm{H} 14$ & 1 & & & & \\
\hline A5 & Habitat & $\mathrm{H} 15$ & 1 & & & & \\
\hline A6 & Pressurized Logistics Module & $\mathrm{H} 16$ & & 1 & & & \\
\hline A7 & Pressurized Logistics Module & $\mathrm{H} 17$ & & 1 & & & \\
\hline A8 & Pressurized Logistics Module & $\mathrm{H} 18$ & & 1 & & & \\
\hline A9 & Unpressurized Rover & $\mathrm{H} 20$ & & & 1 & & \\
\hline A10 & Unpressurized Rover & $\mathrm{H} 21$ & & & 1 & & \\
\hline A11 & Unpressurized Rover & $\mathrm{H} 22$ & & & 1 & & \\
\hline A12 & Unpressurized Rover & $\mathrm{H} 23$ & & & 1 & & \\
\hline A13 & Pressurized Rover & $\mathrm{H} 24$ & & & & 1 & \\
\hline A14 & Pressurized Rover & $\mathrm{H} 25$ & & & & 1 & \\
\hline A15 & Pressurized Rover & $\mathrm{H} 26$ & & & & 1 & \\
\hline A16 & Power Systems & $\mathrm{H} 31$ & & & & & 1 \\
\hline A17 & Power Systems & $\mathrm{H} 32$ & & & & & 1 \\
\hline A18 & Power Systems & $\mathrm{H} 33$ & & & & & 1 \\
\hline A19 & Power Systems & $\mathrm{H} 34$ & & & & & 1 \\
\hline A20 & Power Systems & $\mathrm{H} 35$ & & & & & 1 \\
\hline
\end{tabular}

Table 7. Historical TR Bin Transition Times (Notional).

\begin{tabular}{|l|c|c|c|c|c|}
\hline \multicolumn{1}{|c|}{ Category } & \multicolumn{2}{|c|}{ Bin2 $\rightarrow$ Bin3 } & \multicolumn{2}{c|}{ Bin3 $\rightarrow$ Bin4 } \\
\hline & $\begin{array}{c}\text { Data } \\
\text { Set }\end{array}$ & Mean & Std Dev & Mean & Std Dev \\
\hline Habitat & $\mathrm{H} 11$ & 0.348 & 0.181 & 1.649 & 0.868 \\
\hline Habitat & $\mathrm{H} 12$ & 0.95 & 0.37 & 2.00 & 0.37 \\
\hline Habitat & $\mathrm{H} 13$ & 1.33 & 0.39 & 1.20 & 0.76 \\
\hline Habitat & $\mathrm{H} 14$ & 0.67 & 0.62 & 1.18 & 0.37 \\
\hline Habitat & $\mathrm{H} 15$ & 1.14 & 1.43 & 0.70 & 0.65 \\
\hline Pressurized Logistics Module & $\mathrm{H} 16$ & 0.933 & 0.01 & 0.941 & 1.428 \\
\hline Pressurized Logistics Module & $\mathrm{H} 17$ & 1.92 & 0.92 & 0.56 & 0.77 \\
\hline Pressurized Logistics Module & $\mathrm{H} 18$ & 1.88 & 1.00 & 0.91 & 0.00 \\
\hline Pressurized Logistics Module & $\mathrm{H} 19$ & 0.24 & 0.76 & 0.44 & 0.46 \\
\hline Unpressurized Rover & $\mathrm{H} 20$ & 0.726 & 0.705 & 0.357 & 1.448 \\
\hline Unpressurized Rover & $\mathrm{H} 21$ & 0.31 & 0.67 & 1.31 & 1.39 \\
\hline Unpressurized Rover & $\mathrm{H} 22$ & 0.69 & 0.39 & 0.78 & 0.61 \\
\hline Unpressurized Rover & $\mathrm{H} 23$ & 0.72 & 1.16 & 0.32 & 0.02 \\
\hline Pressurized Rover & $\mathrm{H} 24$ & 1.363 & 0.838 & 0.447 & 1.363 \\
\hline Pressurized Rover & $\mathrm{H} 25$ & 0.73 & 1.30 & 0.47 & 0.98 \\
\hline Pressurized Rover & $\mathrm{H} 26$ & 0.99 & 0.70 & 1.97 & 1.13 \\
\hline Pressurized Rover & $\mathrm{H} 27$ & 1.64 & 1.09 & 1.06 & 1.34 \\
\hline Pressurized Rover & $\mathrm{H} 28$ & 1.09 & 0.47 & 1.25 & 0.68 \\
\hline Pressurized Rover & $\mathrm{H} 29$ & 1.58 & 0.68 & 0.20 & 1.20 \\
\hline Power Systems & $\mathrm{H} 30$ & 0.322 & 0.013 & 0.471 & 1.424 \\
\hline Power Systems & $\mathrm{H} 31$ & 0.01 & 0.19 & 0.17 & 0.66 \\
\hline Power Systems & $\mathrm{H} 32$ & 0.92 & 0.54 & 1.39 & 1.22 \\
\hline Power Systems & $\mathrm{H} 33$ & 1.50 & 0.33 & 1.99 & 0.33 \\
\hline Power Systems & $\mathrm{H} 34$ & 1.16 & 0.55 & 1.94 & 0.98 \\
\hline Power Systems & $\mathrm{H} 35$ & 1.94 & 0.52 & 0.86 & 1.12 \\
\hline & & & & & \\
\hline & & & & \\
\hline
\end{tabular}

The likelihood of achieving the planned IOC dates as shown in Table 5 is plotted as the S-curves in Fig. 3. This plot allows the analysts to quickly assess the likelihood of achieving IOC on any date or to estimate the date when an element will reach a given likelihood. The inset in Fig. 4, which is generated by analyzing resulting data from the probabilistic runs, shows how each historical ATDP of the pressurized logistics module contributes to the delay of that element. These data may be used to prioritize efforts to meet the planned schedule. In this example, priority should be given to the ATDP named A7 because it has a $65 \%$ chance of causing a delay. If A7 is mitigated to the point that it only contributes $40 \%$ or less of the delay, work should also be undertaken to improve A8 because it currently contributes $40 \%$ of the delay. 


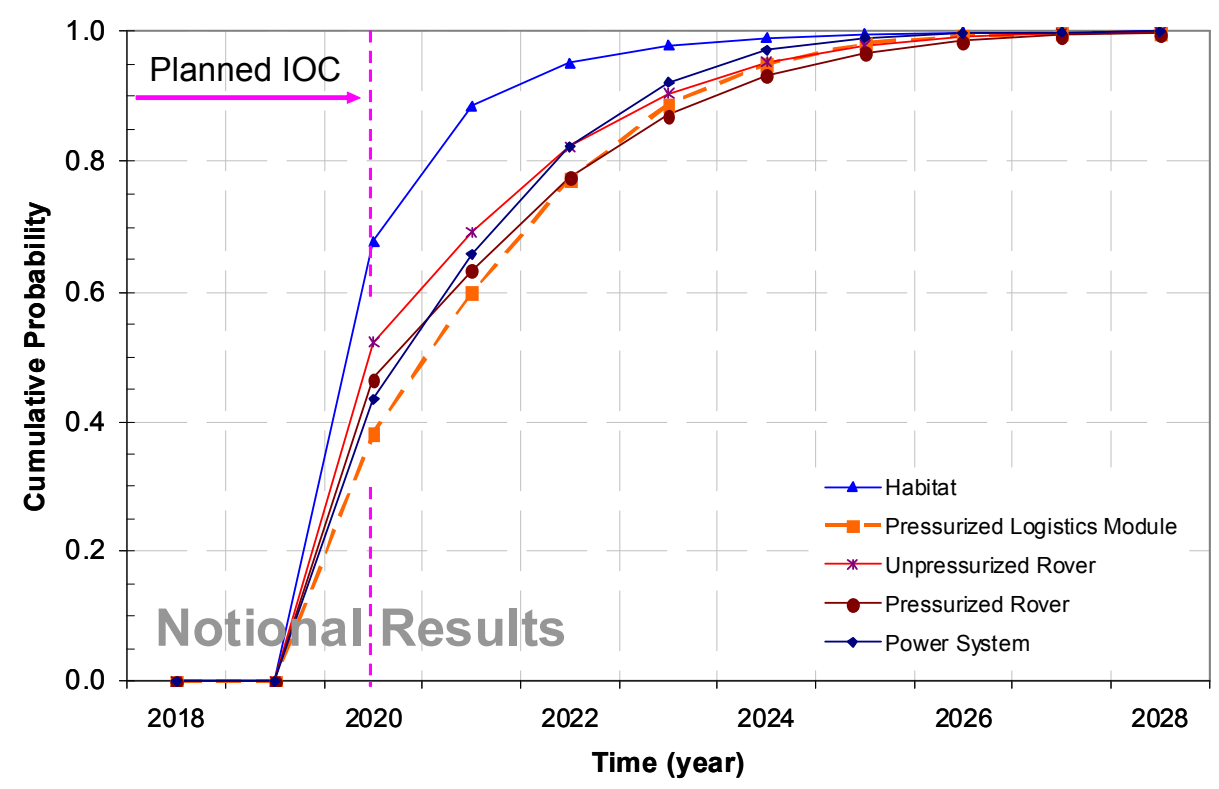

Figure 3. CDF of Estimate IOC Date for Elements.

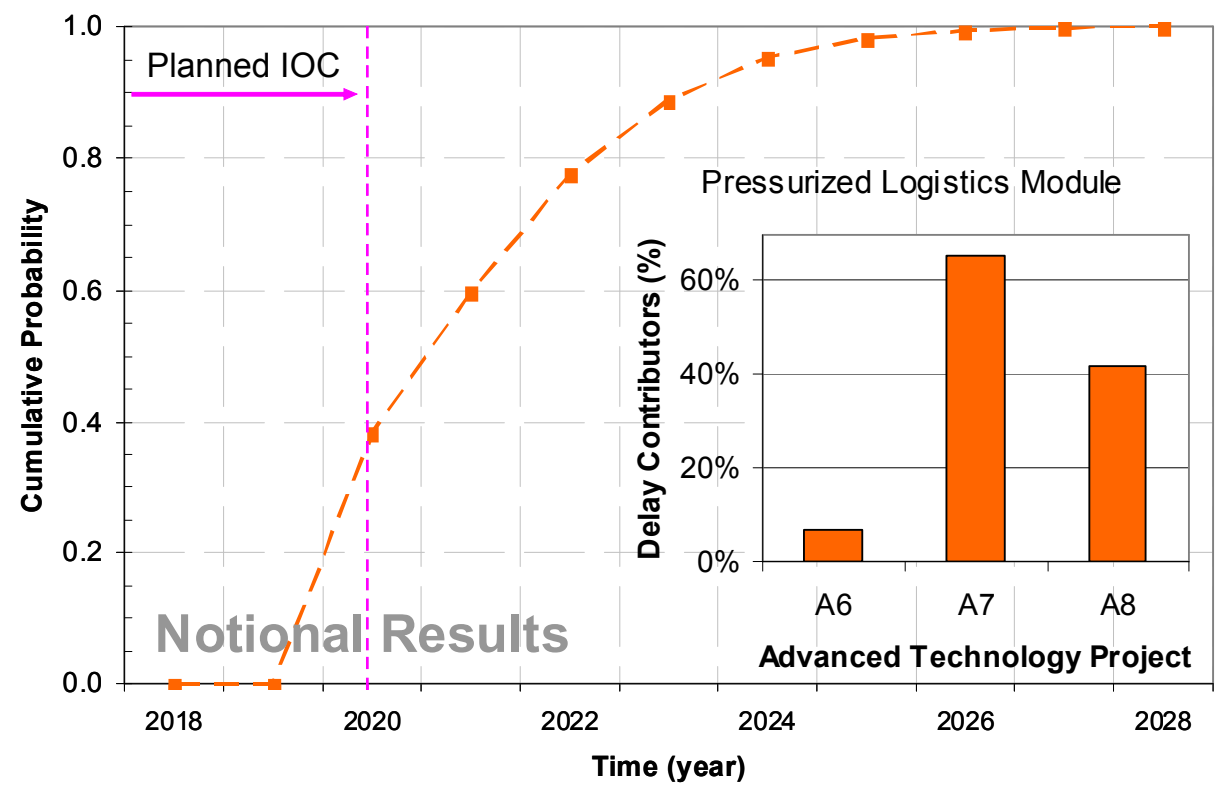

Figure 4. Contributors by ATDP to Delay in an Element.

\section{Conclusion}

The modeling of schedule risks associated with advanced technology development delays is a capability that is still being matured but, as evidenced in this paper, already provides insight into the expected behavior of candidate and planned technology development investments. Discussion herein pointed out that consideration and inclusion of historical data is essential in understanding such risks and that the analysis methodology described by Mathias at al. and Forgie and Evans can be taken a step further by enabling analysis of inter-related elements within an architecture. The methodology also accounts for the impacts of multiple advanced technology developments for each individual architecture element. The current modeling capability leverages a significant amount of historical data collected by Mathias et al. and Forgie and Evans, and is in the process of being updated to reflect the actual inter-relationships between elements. Future work also includes translating modeled schedule delays into actual affordability impacts with emphasis on the fact that delays within one element can often lead to both cost overruns 
within that element's development effort as well as other elements in which it shares a schedule relationship and related affordability constraints.

The end product will provide decision makers insight into planned schedules and costs as a function of historical data analogies to current technology development challenges. Emphasis will be placed on complete visibility into the historical data points that drive the results to improve credibility and insight. Users of the model will also have the capability to dynamically choose between historical data to focus on the examples they feel are the most analogous to the problem at hand.

\section{Acknowledgments}

The authors would like to acknowledge those colleagues who have provided support and historical data. Notably, Donovan Mathias and Susie Go at the NASA Ames Research Center who formulated the basis for this work and have since worked with Cynthia Forgie to collect additional data. Bill Cirillo at the NASA Langley Research Center also provided significant intellectual contribution and advice.

An acknowledgment is also due to the NASA Langley Aerospace Research Summer Scholars Program through which funding was provided for one of the authors.

\section{References}

${ }^{1}$ Stanley, D., and Wilhite, A., "Technology Engineering: The Concurrent Development of Space Transportation Systems and Technology," AIAA Paper 2006-7295, September, 2006.

${ }^{2}$ Olds, J.R, “A Review of Technology Assessment Methods for Space Transportation Systems," Georgia Tech Space Systems Engineering Conference, Atlanta, GA, November, 2005.

${ }^{3}$ Kirby, M.R., "A Methodology for Technology Identification, Evaluation, and Selection in Conceptual and Preliminary Aircraft Design," Ph.D. Thesis, Georgia Institute of Technology, March 2001.

${ }^{4}$ Charania, A., and Olds, J.R., "Application of the Abbreviated Technology Identification Evaluation, and Selection (ATIES)

Methodology to a Mars Orbit Based (MOB) Solar Clipper Architecture," IAC-02-U.5.01, 53 ${ }^{\text {rd }}$ International Astronautical Congress, Toulouse, France, October, 2001.

${ }^{5}$ Shishko, R., Ebbeler, D.H., and Fox, G., "NASA Technology Assessment Using Real Options Valuation," Systems Engineering, Vol. 7, Issue 1, 2004, pp. 1-13.

${ }^{6}$ Wesibin, C., Lincoln, W., Mrozinski, J., Hua, H., Merida, S., Shelton, K., Adumitroaie, V., Derleth, J., and Silberg, R., "Technology Assessment in Support of the Presidential Vision for Space Exploration," Proceedings of the 2006 IEEE/SMC International Conference on System of Systems Engineering, Los Angeles, CA, April 2006, pp. 130-136.

${ }^{7}$ Cavanaugh, S., Chytka, T., Arcana, P., Jones, S., Stanley, D., Wilhite, A., "NASA Langley Systems Analysis \& Concepts Directorate Technology Assessment/Portfolio Analysis," AIAA Paper 2006-7029, September, 2006.

${ }^{8}$ Mankins, J.D., “Technology Readiness Levels,” NASA Office of Space Access and Technology, White Paper, 1995.

${ }^{9}$ Mathias, D.L., Goodsell, A.M., and Go, Susie, "Technology Development Risk Assessment for Space Transportation Systems," Proceedings of the $8^{\text {th }}$ International Conference on Probabilistic Safety Assessment and Management, Paper 0211, New Orleans, LA, May, 2006.

${ }^{10}$ Exploration Systems Architecture Study - Final Report, NASA-TM-2005-214062, November 2005.

${ }^{11}$ Forgie, C., and Evans, G., "Planning and Risk Assessment for Long Range Technology Programs," Proceedings of the 2008 Industrial Engineering Research Conference, Vancouver, British Columbia, Canada, May 2008. 